\title{
Análise de Desempenho de Evolução Acadêmica e Profissional de Alunos do Curso de Engenharia Civil após a Entrada no Programa de Educação Tutorial
}

DOI: 10.37702/2175-957X.COBENGE.2021.3493

Laura Mendonça Ponte Souza - laura.souza@itec.ufpa.br

Universidade Federal do Pará

R Antônio Barreto 1040

66060-020 - Belém - PA

Nivia da Silva Lisboa - nivia.lisboa@itec.ufpa.br

Universidade Federal do Pará

RUA NOSSA SENHORA DE FATIMA 467

66615-140 - Belém - PA

Gabriel Melém Maués - gmelemm@gmail.com

Universidade Federal do Pará

Passagem Salvador 40

66113-210 - Belém - PA

Nívea G B Albuquerque - nivea@ufpa.br

Universidade Federal do Pará

C) IMPERIO AMAZONICO 15

66613-080 - BELEM - PA

Resumo: O Programa de Educação Tutorial - Engenharia Civil (PET-Civil) surgiu como forma de unir experiências ao agregar as esferas de ensino, pesquisa e extensão em um ambiente acadêmico, permitindo ao aluno experiências formativas externas à sala de aula. Ao longo dos anos e com a evolução constante das diversas formas de integração entre aluno, faculdade e sociedade, o programa passou por diversas mudanças em sua forma de atingir a comunidade acadêmica surge, portanto, necessário avaliar como o programa e a participação dos alunos atinge o progresso pessoal e a qualidade da graduação como um todo. O seguinte trabalho tem por objetivo avaliar os impactos da participação dos grupos PET-Civil sobre o desenvolvimento profissional, acadêmico e pessoal de seus egressos ao longo dos anos de 2019 e 2020, buscando compreender, principalmente, se o 
grupo vem cumprindo com seus objetivos conforme traçados pelo Ministério da Educação e se o mesmo possuiu influência positiva quanto à formação de seus participantes, através de resultados obtidos por meio de uma pesquisa realizada com 15 alunos egressos dos grupos Pet-Civil. A pesquisa teve como principais pontos abordados o perfil dos atores envolvidos e o impacto na formação acadêmica considerando principalmente média acadêmica e ingresso no mercado de trabalho e continuidade dos estudos (pós-graduações).

Palavras-chave: Programa de Educação Tutorial. Engenharia Civil. Formação Acadêmica. Ensino. Educação. 


\section{Análise de Desempenho de Evolução Acadêmica e Profissional de Alunos do Curso de Engenharia Civil após a Entrada no Programa de Educação Tutorial}

\section{INTRODUÇÃO}

O Programa de Educação Tutorial (PET) foi criado em 1979, inicialmente chamado por Programa Especial de Treinamento, tendo o intuito inicial de estimular a produção acadêmica nas universidades em função da explosão nas universidades públicas durante as décadas de 60-70, época em que a educação superior brasileira se mostrava carente com relação à qualidade e desempenho do ensino como um todo, evidenciando a necessidade de métodos que promovessem o ensino, pesquisa e extensão durante a graduação de forma mais eficiente. O Programa de Educação Tutorial (PET) foi então implementado 1979, sendo destinado a grupos de alunos que apresentassem rendimento acadêmico satisfatório, comprovado por meio de histórico escolar, e interesse em ingressar na carreira acadêmica, em diversos cursos de graduação de Instituições de Ensino Superior públicas do Brasil (PETRILLI-FILHO; MARTINS, 2001; SPAGNOLO; CASTRO; PAULO FILHO, 1996).

O Programa é vinculado à Secretaria de Ensino Superior (SESu) do MEC desde 1999 e atualmente conta com mais de 800 grupos distribuídos entre 121 Instituições de Ensino Superior. Durante seu período de existência, diversas análises acerca dos impactos do PET na graduação dos discentes já foram feitas: diferentes trabalhos como os de Artuzo et al. (2012), Matos et al. (2010), Pizzinato et al. (2010) e Silva (2015) trataram dos impactos do PET nas áreas da tríade acadêmica, bem como as influências do Programa na trajetória profissional e acadêmica de seus egressos, a fim de demonstrar sua importância e buscar melhorias constantes.

No contexto da Engenharia Civil, bem como outros cursos relacionados à área de exatas, são evidentes as dificuldades no que diz respeito ao desempenho acadêmico dos discentes em comparação com cursos de outras áreas do conhecimento, muito em função de deficiências advindas do ensino médio - segundo o Mapa do Ensino Superior de 2020, o número de ingressantes no curso de Engenharia Civil nas universidades públicas do país foi de 57.413. No ano de 2016, observou-se que apenas $54,2 \%$ dos ingressantes em um dos cursos de engenharia em geral o concluem, evidenciando a dificuldade quanto à estabilidade dos discentes ao longo da vivência no ensino superior como um todo - um estudo feito pelo programa de pós-graduação em Ensino de Ciências e Matemática, da Universidade Cruzeiro do Sul em 2016, investigou os motivos da evasão em cursos de Engenharia: o censo comprovou, após a análise de 259 artigos sobre o tema, apresentados no Congresso Brasileiro de Educação em Engenharia (COBENGE) entre os anos de 2000 e 2014, que "existe uma forte relação entre evasão e a reprovação nas disciplinas do ciclo básico".

De posse dessas informações, possuindo como questão norteadora "Qual a influência do PET na formação dos alunos de Engenharia Civil?", este trabalho teve por objetivo geral analisar as influências da participação no grupo PET Civil na formação profissional e pessoal dos discentes, a partir do estudo da vivência de alunos egressos dos anos de 2019 e 2020 em diversas universidades públicas do país. Para isso, definiu-se como objetivos específicos: caracterizar os ex-integrantes do PET, bolsistas e voluntários, quanto ao tempo de permanência no Programa; identificar a evolução do desempenho acadêmico durante o tempo de participação no Programa através de índices como coeficiente de rendimento geral ao longo dos semestres; analisar como as atividades 
desenvolvidas no grupo influenciam na formação profissional e pessoal do aluno como um todo.

\section{METODOLOGIA}

O intuito da pesquisa é um estudo qualitativo, que teve como objeto o Programa de Educação Tutorial (PET) do curso de Engenharia Civil de diferentes localidades do país. Participaram da pesquisa 15 (quinze) discentes egressos, sendo 3 (três) da Universidade Federal de São Carlos (UFSCAR), 4 (quatro) da Universidade Federal de Juiz de Fora (UFJF), 4 (quatro) da Universidade Federal de Uberlândia (UFU) e 4 da Universidade Federal do Pará. Inicialmente, foi elaborado um formulário na plataforma Google Forms: os dados foram coletados por meio de entrevista semiestruturada, contendo perguntas abertas e fechadas para ex-alunos, tendo sido aplicada no período de abril de 2021. Foram elaboradas 8 (oito) perguntas subjetivas e objetivas com o intuito de investigar o perfil dos egressos e a influência da participação no grupo PET quanto ao percurso profissional, acadêmico e pessoal do indivíduo. As perguntas objetivas apresentavam afirmações quanto à influência do programa em determinadas situações como ingresso no mercado de trabalho e na pós-graduação, apresentando uma faixa numérica de 0 (zero) a 5 (cinco), onde 0 demonstrava total discordância com a afirmação e 5 total concordância. Abriu-se também um espaço para comentários pessoais acerca do grupo, possibilitando visualizar opiniões sobre diversas áreas e situações.

De posse do questionário, realizou-se um mapeamento do grupo alvo a partir da pesquisa em sites oficiais de grupos PET-Civil com o intuito de localizar possíveis contatos de discentes egressos dos grupos. Obtidas as informações, foi possível proceder à fase de pesquisa: o formulário foi enviado por meio de redes sociais como Facebook e WhatsApp para os egressos, para que os dados pudessem então ser coletados e analisados. Foram estabelecidos como critério de inclusão no estudo: ter feito parte do PET-Civil em uma universidade pública do país; manifestar livre interesse em participar da pesquisa após o esclarecimento dos objetivos da pesquisa e da garantia de sigilo e anonimato das informações fornecidas. Os dados foram então analisados e processados estatisticamente por meio do software Microsoft Excel após terem sido organizados em planilhas conforme cada pergunta objetiva. Foram identificadas as diferentes categorias de análise: perfil dos egressos participantes; influência do PET na formação profissional do aluno; influência do PET na formação acadêmica do aluno. $O$ anonimato das informações foi assegurado no ato do consentimento informado no início do formulário, e os indivíduos do estudo foram identificados com iniciais aleatórias, como A.B e C.D.

\section{RESULTADOS E DISCUSSÕES}

Os dados foram coletados no período de abril de 2021, totalizando 15 respostas de alunos egressos do Programa de Educação Tutorial dos cursos de Engenharia Civil de três diferentes universidades do país. Dos 15 alunos analisados, 3 (três) eram discentes da Universidade Federal de São Carlos (UFSCAR), 4 (quatro) eram discentes da Universidade Federal de Juíz de Fora (UFJF), 4 eram discentes da Universidade Federal de Uberlândia (UFU) e os quatro restante eram discentes da Universidade Federal do Pará (UFPa). Para facilitar a análise dos dados coletados pelo questionário, os resultados foram organizados em dois agrupamentos diferentes: 1) impactos acadêmicos, 2) impactos profissionais.

O Quadro 1 apresenta a distribuição dos egressos analisados conforme semestres de entrada de saída e tempo de permanência no grupo; observa-se que, com exceção de poucos casos, a maior parte dos discentes permaneceu por pelo menos três semestres, em 
sua maioria deixando o grupo apenas no momento da graduação $\left(9^{\circ}\right.$ e $10^{\circ}$ semestres, isso em função das diferenças de carga horária entre os turnos diurno e noturno). A maior parte dos discentes ingressou nos semestres iniciais do curso enquanto apenas duas pessoas ingressaram após o sétimo período, o que se pode atribuir ao fato de que o interesse em ingressar no grupo é reduzido nos períodos finais do curso em função da redução do aproveitamento das atividades do grupo em função de outras ocupações e foco em atividades terceiras como estágios e monitorias, por exemplo.

QUADRO 1 - Distribuição do perfil dos discentes analisados quanto ao sexo, semestres de entrada e saída e tempo de permanência no grupo.

\begin{tabular}{|ccc|}
\hline Semestre de Entrada & Semestre de Saída & Tempo de Permanência \\
\hline $3^{\circ}$ semestre & $6^{\circ}$ semestre & 3 semestres \\
$3^{\circ}$ semestre & $7^{\circ}$ semestre & 4 semestres \\
$3^{\circ}$ semestre & $8^{\circ}$ semestre & 5 semestres \\
$4^{\circ}$ semestre & $9^{\circ}$ semestre & 5 semestres \\
$5^{\circ}$ semestre & $9^{\circ}$ semestre & 4 semestres \\
$2^{\circ}$ semestre & $6^{\circ}$ semestre & 4 semestres \\
$8^{\circ}$ semestre & $10^{\circ}$ semestre & 2 semestres \\
$2^{\circ}$ semestre & $9^{\circ}$ semestre & 7 semestres \\
$4^{\circ}$ semestre & $9^{\circ}$ semestre & 5 semestres \\
$3^{\circ}$ semestre & $7^{\circ}$ semestre & 4 semestres \\
$7^{\circ}$ semestre & $9^{\circ}$ semestre & 2 semestres \\
$3^{\circ}$ semestre & $8^{\circ}$ semestre & 5 semestres \\
$2^{\circ}$ semestre & $9^{\circ}$ semestre & 7 semestres \\
$3^{\circ}$ semestre & $7^{\circ}$ semestre & 4 semestres \\
$3^{\circ}$ semestre & $8^{\circ}$ semestre & 5 semestres \\
\hline
\end{tabular}

Fonte: Elaboração própria a partir da pesquisa executada

\section{Impacto na Vida Acadêmica}

Foi solicitado aos discentes que respondessem escolhendo um número, entre 0 e 5 na faixa numérica, de acordo com o nível de conformidade com a afirmação em questão. $A$ Figura 1 mostra a distribuição das respostas com relação à primeira pergunta: "Com relação à vida acadêmica, você diria que a sua participação no grupo PET-Civil influenciou positivamente quanto à sua evolução acadêmica? (coeficiente de rendimento geral, por exemplo)".

A influência no grupo no que diz respeito aos índices acadêmicos dos discentes foi relativa - dos 15 respondentes, 6 (40\%) concordaram totalmente com a afirmação, enquanto $5(33,4 \%)$ mostraram-se imparciais. É importante levar em consideração o fato de que o PET tem como público-alvo discentes com desempenho acadêmico satisfatório, portanto, os participantes da pesquisa já possuíam desempenho elevado anteriormente à entrada no grupo - porém, é importante analisar a partir deste estudo se a participação no grupo foi importante para a manutenção desses índices acadêmicos, isto é, se o grupo forneceu apoio acadêmico e maiores possibilidades de estudo aos discentes com relação a diferentes disciplinas da graduação, seja pela presença de tutorias ou oportunidades de acesso a livros e outros materiais relativos à graduação, por exemplo.

Para fomentar a análise, foram analisados os históricos acadêmicos dos respondentes, levando em consideração o desempenho durante os semestres anteriores à entrada do discente e a evolução desses índices acadêmicos ao longo da participação do 
discente no grupo. Para os 15 respondentes, foi calculado o coeficiente de rendimento médio para os semestres anteriores à entrada do discente no PET-Civil e novamente para os semestres em que o discente participou. Os resultados são mostrados conforme a Figura 1 e o Quadro 2:

Figura 1 - Distribuição de conformidade conforme a seguinte afirmação: O grupo PET-Civil influenciou positivamente com relação à evolução acadêmica do discente.

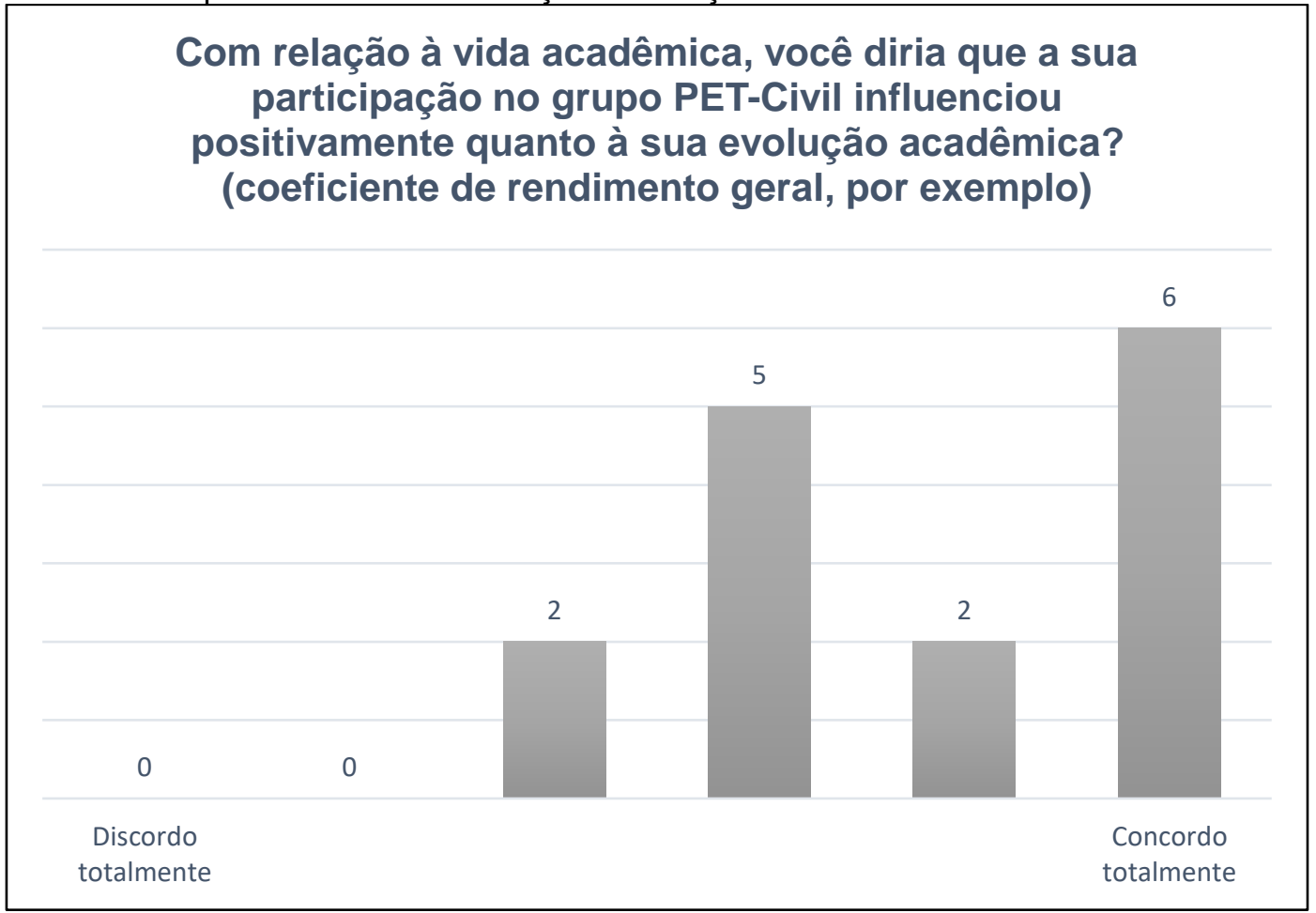

Fonte: Elaboração própria a partir da pesquisa executada

Quadro 2 - Distribuição dos coeficientes de rendimento médio dos discentes antes e após a entrada no PET-Civil, em função do tempo de permanência no grupo

\begin{tabular}{|lcccc|}
\hline $\begin{array}{c}\text { Semestre } \\
\text { de Entrada }\end{array}$ & $\begin{array}{c}\text { Semestre de } \\
\text { Saída }\end{array}$ & $\begin{array}{c}\text { Tempo de } \\
\text { Permanência }\end{array}$ & $\begin{array}{c}\text { Coeficiente de } \\
\text { Rendimento Anterior à } \\
\text { Entrada no Grupo }\end{array}$ & $\begin{array}{c}\text { Coeficiente de } \\
\text { Rendimento Durante } \\
\text { a Participação no } \\
\text { Grupo }\end{array}$ \\
\hline $3^{\circ}$ semestre & $6^{\circ}$ semestre & 3 semestres & 7,46 & 8,52 \\
$3^{\circ}$ semestre & $7^{\circ}$ semestre & 4 semestres & 6,58 & 8,35 \\
$3^{\circ}$ semestre & $8^{\circ}$ semestre & 5 semestres & 8,38 & 8,95 \\
$4^{\circ}$ semestre & $9^{\circ}$ semestre & 5 semestres & 8,19 & 8,50 \\
$5^{\circ}$ semestre & $9^{\circ}$ semestre & 4 semestres & 7,75 & 8,96 \\
$2^{\circ}$ semestre & $6^{\circ}$ semestre & 4 semestres & 8,50 & 8,75 \\
$8^{\circ}$ semestre & $10^{\circ}$ semestre & 2 semestres & 6,59 & 8,32 \\
$2^{\circ}$ semestre & $9^{\circ}$ semestre & 7 semestres & 7,50 & 8,57 \\
$4^{\circ}$ semestre & $9^{\circ}$ semestre & 5 semestres & 7,36 & 7,89 \\
$3^{\circ}$ semestre & $7^{\circ}$ semestre & 4 semestres & 5,89 & 7,85 \\
$7^{\circ}$ semestre & $9^{\circ}$ semestre & 2 semestres & 7,58 & 8,20 \\
$3^{\circ}$ semestre & $8^{\circ}$ semestre & 5 semestres & 6,58 & 7,83 \\
$2^{\circ}$ semestre & $9^{\circ}$ semestre & 7 semestres & 7,50 & 8,54 \\
$3^{\circ}$ semestre & $7^{\circ}$ semestre & 4 semestres & 6,63 & 7,55 \\
$3^{\circ}$ semestre & $8^{\circ}$ semestre & 5 semestres & 7,32 & 8,56 \\
\hline
\end{tabular}

Fonte: Elaboração própria a partir da pesquisa executada 
Os resultados evidenciam a manutenção dos índices acadêmicos - anteriormente à entrada no grupo, a média do coeficiente de rendimento dos discentes é de 7,32. Mesmo para respondentes com tempos de participação menores (2-3 semestres), o rendimento tendeu a se manter ou melhorar nos semestres seguintes, com uma média de 8,36; a pesquisa optou, ainda, por abrir um espaço de maior subjetividade para que os egressos pudessem se comentar quanto à participação no grupo e a contribuição do Programa com relação ao rendimento acadêmico. Alguns dos comentários feitos seguem transcritos abaixo:

"Acredito que o PET me ajudou a amadurecer dentro da graduação, aprendi a lidar melhor com minhas responsabilidades e a me organizar melhor. Além disso, a cada dia aprendo a trabalhar melhor em grupo e a defender minhas opiniões." (A.B.)

"A participação no PET influenciou positivamente minha vida acadêmica, profissional e pessoal. Quanto à vida acadêmica, me possibilitou: mais contato com professores; contato com alunos de períodos posteriores ao meu; conhecimento de softwares; apoio nos estudos" (C.D.)

"O PET civil atuou positivamente em todos os aspectos mencionados, principalmente do que diz respeito ao desenvolvimento de habilidades como comunicação e profissionalismo. Destaco, porém, alguns aspectos sobre a minha participação que podem ser interessantes ao grupo: O PET ajudou no desenvolvimento acadêmico principalmente no que diz respeito à produção de artigos e participação em eventos científicos, porém não teve absolutamente nenhuma influência em aspectos como CRG." (E.F.)

Embora a manutenção e aumento do rendimento tenha sido evidente, isso pode ser explicado por motivos alheios à participação no grupo, uma vez que a pesquisa tem certo viés: o grupo PET é direcionado a alunos que já possuem desempenho acadêmico dentro ou acima da média, de modo que muitos respondentes já demonstravam desempenhos satisfatórios anteriormente à entrada no grupo, tendendo a continuar assim ao longo do curso, em condições normais. Os comentários feitos pelos respondentes, junto às respostas adquiridas no questionário, evidenciam a influência positiva no grupo quanto ao desempenho acadêmico, porém, alguns dos discentes permaneceram imparciais, demonstrando que a influência do PET nesse contexto é menos expressiva.

Foi solicitado também que os discentes respondessem, escolhendo um número entre 0 e 5, de acordo com o nível de conformidade com a pergunta em questão: "Com relação à vida acadêmica, você diria que a sua participação no grupo PET-Civil influenciou positivamente quanto ao seu ingresso em uma pós-graduação? (mestrado acadêmico ou profissional, por exemplo)". A Figura 2 mostra a distribuição das respostas conforme o questionário.

A influência do grupo PET-Civil com relação à vida acadêmica dos discentes é expressiva - dos 15 respondentes, 6 (40\%) concordaram fortemente com a afirmação, enquanto $5(33 \%)$ se mostraram imparciais. Isso pode se dar por diversos motivos, como 0 fato de alguns discentes optarem por não seguir a carreira acadêmica logo após a graduação, por exemplo; com relação às influências positivas, isso se dá principalmente pelo índice de produções acadêmicas e projetos voltados para a comunidade acadêmica como forma geral: os discentes participantes demonstram ter maior domínio com relação a competências como escrita científica e projetos extracurriculares, tornando-se fortes candidatos em diversas instituições de ensino superior. 
Figura 2 - Distribuição de conformidade conforme a seguinte afirmação: O grupo PET-Civil influenciou positivamente com relação ao ingresso em uma pós-graduação.

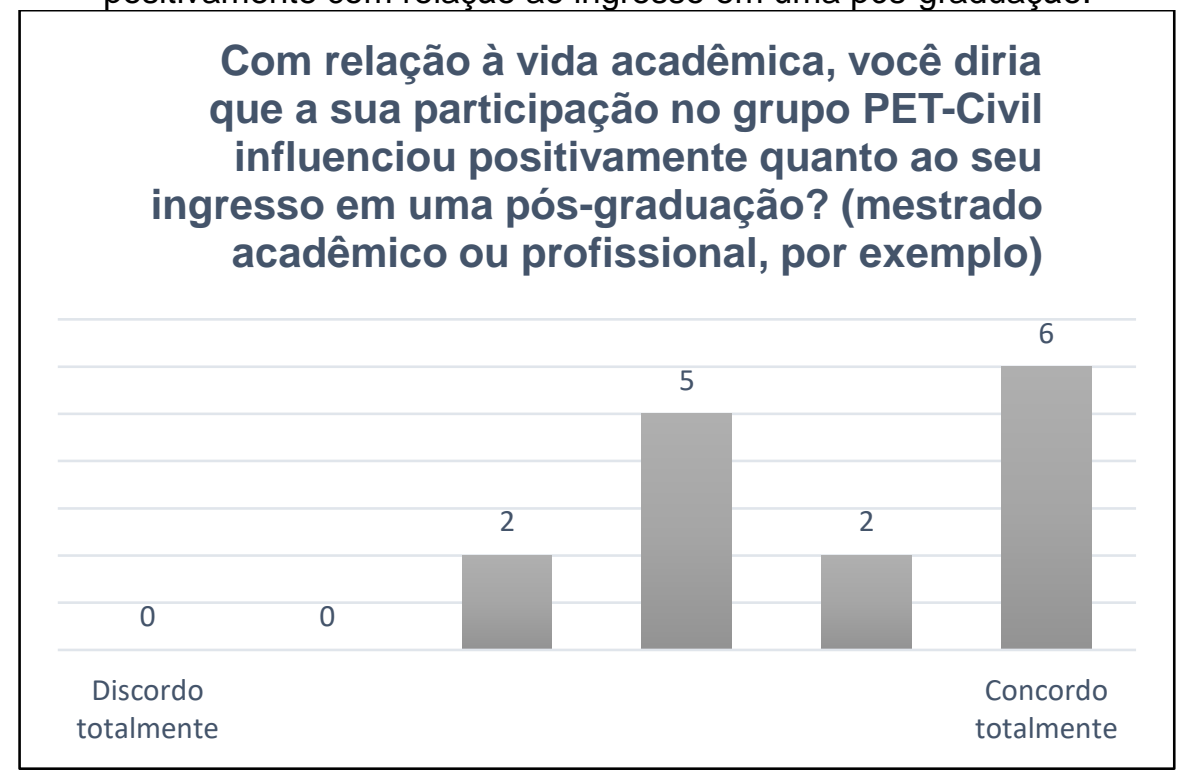

Fonte: Elaboração própria a partir da pesquisa executada

\section{Impacto na Vida Profissional}

Foi solicitado que os discentes respondessem escolhendo um número, entre 0 e 5 , de acordo com o nível de conformidade com a afirmação em questão. A Figura 3 mostra a distribuição das respostas com relação à pergunta: "Com relação à vida profissional, você diria que a sua participação no grupo PET-Civil influenciou positivamente quanto ao seu ingresso no mercado de trabalho? (entrevistas de emprego, por exemplo)".

Figura 3 - Distribuição de conformidade conforme a seguinte afirmação: O grupo PET-Civil influenciou positivamente com relação ao ingresso no mercado de trabalho.

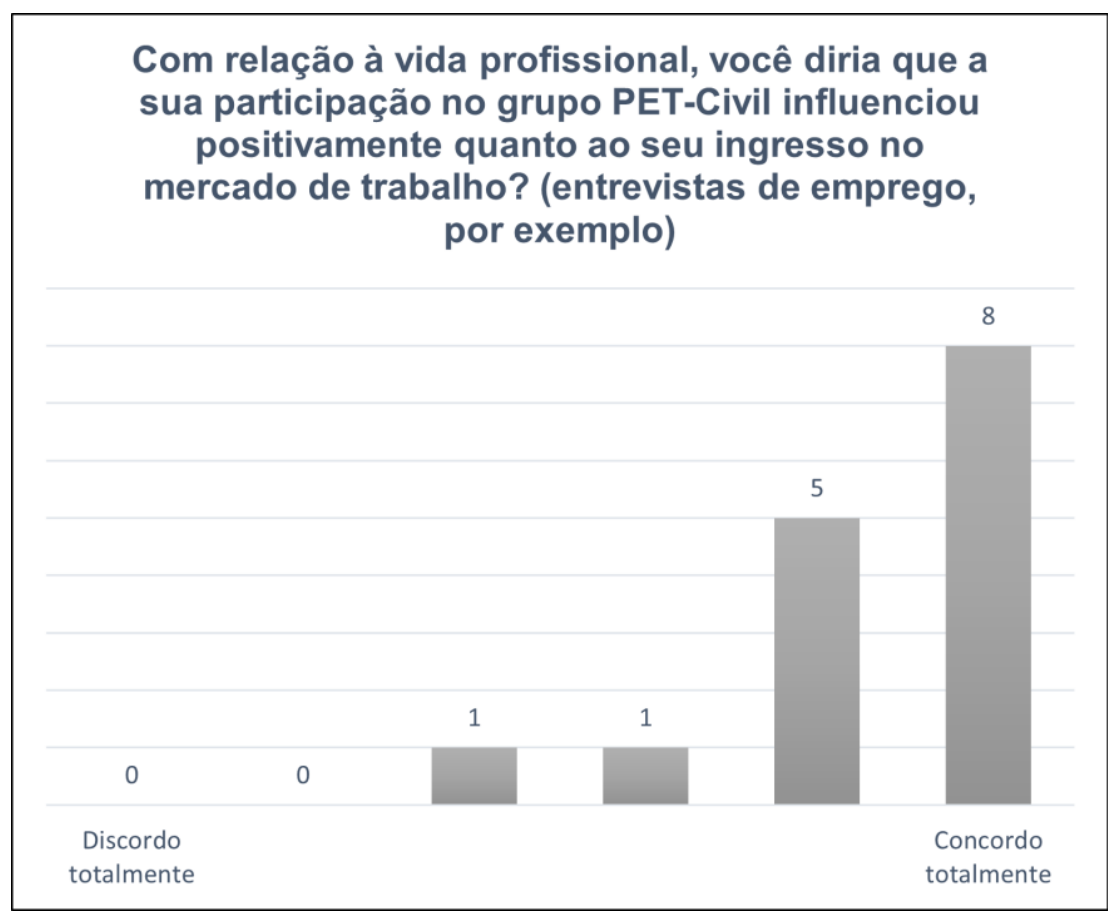

Fonte: Elaboração própria a partir da pesquisa executada 
A influência do PET na trajetória profissional de seus egressos é ainda mais expressiva - dentre os respondentes, apenas 2 de 15 afirmaram que o grupo não influenciou de forma positiva com relação ao ingresso no mercado de trabalho, embora possam estar buscando outros caminhos como a pós-graduação, por exemplo.

Dos 15 respondentes, 53\% afirmaram que a participação no grupo PET influenciou positivamente com relação ao ingresso no mercado de trabalho - isso pode se dar por diversos fatores, como a experiência gerada pelas atividades propostas pelo grupo, tanto em âmbito acadêmico como profissional, por exemplo: a oportunidade de executar atividades mais próximas ao ambiente profissional e acadêmico fora da sala de aula, bem como o desenvolvimento de diversas habilidades voltadas para a vida profissional como diferentes softwares mostra-se um fator diferencial positivo no que diz respeito à escolha de profissionais qualificados.

Ainda, a pesquisa optou por abrir um espaço de maior subjetividade para que os expetianos pudessem se expressar quanto às suas opiniões com relação à participação no grupo e a contribuição do Programa com relação à vida profissional e pessoal. Alguns dos comentários feitos com relação à influência do PET-Civil a respeito do ingresso no mercado de trabalho seguem transcritos abaixo:

"A principal atuação do PET a meu ver foi o network possibilitado. Desenvolvimento de soft skills (relacionamento interpessoal, oratória, liderança, trabalho em equipe) e incremento de currículo são outras atuações importantes." (G.H.)

"Com certeza contribuiu muito principalmente para trabalhar em grupo, falar em público, resolver problemas de forma rápida, além de aprendizados específicos sobre softwares e áreas da engenharia civil. Com certeza muito enriquecedor." (I.J.)

"A participação no PET influenciou positivamente minha vida acadêmica, profissional e pessoal. Com relação à vida acadêmica, me possibilitou mais contato com professores; contato com alunos de períodos posteriores ao meu; com relação à vida profissional: aquisição de hard e soft skill; experiência com a docência, experiência em organização de eventos; habilidade de lidar com pessoas; trabalho em grupo; gestão; networking (uma vez que petianos egressos muitas vezes indicam para estágios)." (K.L.)

"O PET civil atuou positivamente em todos os aspectos mencionados, principalmente do que diz respeito ao desenvolvimento de habilidades como comunicação e profissionalismo. Destaco, porém, alguns aspectos sobre a minha participação que podem ser interessantes ao grupo: Não estou inserida no mercado de trabalho atualmente, portanto a minha resposta à primeira questão se limita somente às entrevistas que participei após a saída da universidade. Nelas, quando detalhava minha participação no PET, o entrevistador demonstrava muito pouco interesse no assunto. Porém acredito que competências desenvolvidas no grupo, como liderança, me ajudariam no exercer da profissão." (M.N.)

Fica evidente que, mesmo que de forma indireta, a participação no grupo possibilita o desenvolvimento de diversas competências importantes para o mercado de trabalho, desde o desenvolvimento de habilidades profissionais como diferentes softwares e competências quanto à comunicação e relações pessoais até o desenvolvimento de 
networking, possibilitando referências e indicações diversas por ex-alunos, tutores e professores de forma geral. Para fomentar a análise, foi feita outra pergunta: "Com relação à vida pessoal, você diria que a sua participação no grupo PET-Civil influenciou positivamente quanto ao seu desenvolvimento de hard skills? (capacitações em diferentes habilidades, como Excel e outros softwares, por exemplo)"

As respostas foram distribuídas conforme a Figura 4:

Figura 4 - Distribuição de conformidade conforme a seguinte afirmação: O grupo PET-Civil influenciou positivamente com relação ao desenvolvimento de hard skills.

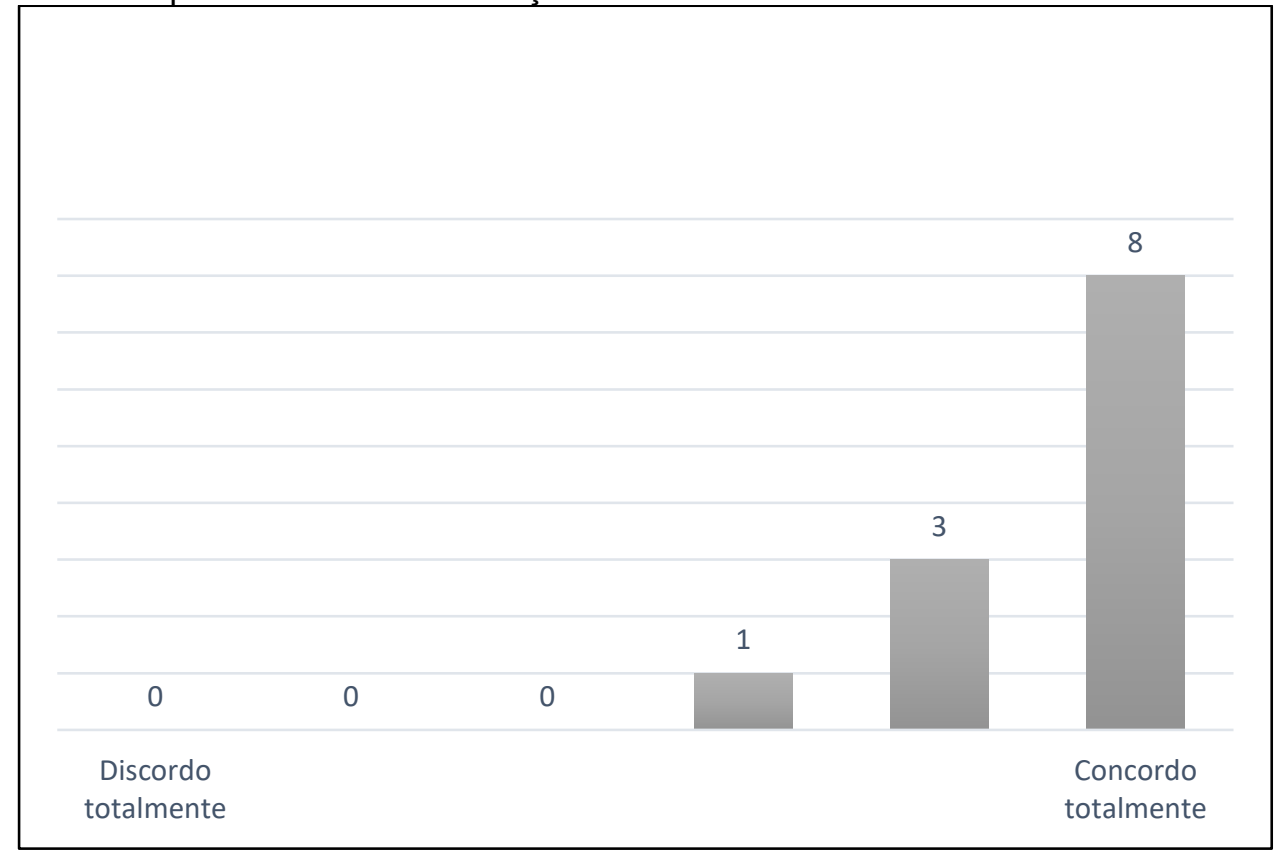

Fonte: Elaboração própria a partir da pesquisa executada

As respostas evidenciam que a influência do PET é expressivamente positiva quanto ao desenvolvimento de hard skills para os discentes - $8(53 \%)$ dos 15 discentes concordaram totalmente com a afirmação. Isso se dá principalmente em função do alto número de projetos desenvolvidos pelo grupo com foco no desenvolvimento dessas habilidades, como cursos, workshops e outros projetos voltados para a comunidade acadêmica como um todo.

\section{CONCLUSÕES}

O presente artigo buscou relatar as influências dos diversos grupos PET-Civil das universidades do país com relação à evolução acadêmica, profissional e pessoal dos discentes - de forma geral, os resultados obtidos demonstram os impactos positivos no grupo quanto ao desempenho profissional, por meio do desenvolvimento de diversas habilidades importantes para o mercado de trabalho através de cursos, workshops e outras atividades, bem como no desempenho acadêmico, por meio das constantes oportunidades de produções acadêmicas e diversos projetos voltados para a comunidade acadêmica.

A experiência de participação no grupo foi unanimemente positiva, e os egressos relataram que o Programa foi de fundamental importância durante a vida acadêmica ao influenciar o desenvolvimento acadêmico e profissional bem como fornecer a possibilidade de entrar em contato com diversas áreas de atuação, despertando o interesse na continuidade dos estudos na forma de pós-graduações ou facilitando o ingresso no mercado de trabalho de diversas formas. 
Apesar disso, é evidente que os grupos podem influenciar de forma mais intensa no que diz respeito à evolução dos índices acadêmicos, uma vez que é de suma importância o auxílio nas mais diversas disciplinas da graduação, principalmente as que dispuserem de maiores índices de reprovação; é importante também intensificar o foco em produções acadêmicas e projetos voltados para a comunidade, intensificando a qualificação dos discentes para o mercado de trabalho e para a vida acadêmica como um todo.

Os resultados são coerentes com os demais estudos realizados em outros Programas de diversas universidades - o trabalho em equipe e a execução de projetos para a comunidade foram aspectos observados como positivos pelos egressos, bem como o apoio ao desenvolvimento de senso crítico e o favorecimento de um maior envolvimento na vida acadêmica e profissional: diversos egressos fomentaram a importância das atividades realizadas no PET após ingressar na pós-graduação e no mercado de trabalho.

A comunidade também segue sendo fortemente beneficiada pelo Programa: as atividades de extensão que fomentam o conhecimento produzido na universidade seguem sendo de suma importância para o grupo. Desta forma, os diversos grupos PET-Civil analisados contemplam de forma positiva a tríade universitária: ensino-pesquisa-extensão, de modo que, com as melhorias previstas a partir dos estudos realizados, seguirão com as atividades de forma correta e eficiente.

\section{REFERÊNCIAS}

ARAÚJO, J R. A.; SILVA, L. M. D., SILVA, S. M. D., SILVA; E. C. DA, \& VASCONCELOS, A. L. F. D. S. (2015). Uma Avaliação de Desempenho Acadêmico dos Bolsistas do Programa Pet- Conexões de Saberes nos Campus da Universidade Federal de Pernambuco em Recife, Caruaru (Centro Acadêmico do Agreste - Caa) e Vitória de Santo Antão (Centro Acadêmico de Vitória - Cav), 1-16.

Balau-roque, M. M., Soely, O., \& Jorge, A. (2012). Dissertação De Mestrado A Experiência No Programa De Educação Tutorial (Pet) E a Formação Do Estudante Do Ensino Superior.

Brant, J., Pereira, A., Carolina, M., Miranda, C. De, \& Riggio, G. F. (2020). MEMÓRIA PET EVOLUÇÃO E CONTRIBUIÇÕES DO PROGRAMA DE EDUCAÇÃO TUTORIAL: 53-81.

DIAS, A. M. I; CÁCERES, E. N.; MARTINS, I. M. L.; GOUVEIA, S. T. (Orgs) Estudo sobre os egressos do Programa de Educação Tutorial / PET 1979 - 2008 MEC/SESu. Fortaleza/CE: Brasil Tropical, 2009.

GOULART, A. T. A importância da pesquisa e da extensão na formação do estudante universitário e no desenvolvimento de sua visão crítica Horizonte, Belo Horizonte, v.2, n.4, p.60-73, 2004.

MARTIN, M. da G. M. (2005) O Programa de educação Tutorial: Formação ampla na graduação. 96p. Dissertação (Mestrado em Educação) - UFP, Curitiba / PR.

MÜLLER, A. (2003) Qualidade no Ensino Superior: a luta em defesa do Programa especial de treinamento. Rio de Janeiro: Editora Garamond.

PERES, S., BOSCARIOLI, C., FERRARI, A., COSTA, C., ALVES, C., SALLES, C., BRUSCATTO, G., SILVA, G., SILVA, L., SOUZA, L., TEIXEIRA, M., DELMONDES, P., \& 
WAGNER, P. (2014). O Programa de Educação Tutorial no contexto da graduação em Computação: Perfis, percepções e reflexões. XXII Workshop Sobre Educação Em Computação - WEI. Anais Do XXXIV Congresso Da Sociedade Brasileira de Computação - CSBC., 1535-1544.

RISTOFF, D. (1999). Universidade em foco: Reflexões sobre a educação superior. São Paulo: Editora Insular, 1999.

SILVA, M. M. F. da, SOUZA, J. P. de, LEITE, L. B., Morais, B. A. de, ALMEIDA, C. L., SILVA, L. G. F. da, MIRANDA, S. V., COSTA, M. C. da S., \& ARAÚJO, V. H. D. (2017). 0 pet-educação no contexto da formação acadêmica: as licenciaturas em evidência. Revista on Line de Política e Gestão Educacional, 3(3), 1499-1516.

Silva, V., Cruz, J., \& Camargo, C. (2008). O Programa De Educação Tutorial (Pet) Como Instrumento Pedagógico Para Os Alunos De Enfermagem. 57-66.

\title{
PERFORMANCE ANALYSIS OF THE ACADEMIC AND PROFESSIONAL EVOLUTION OF STUDENTS IN THE CIVIL ENGINEERING MAJORS AFTER ENTERING THE TUTORIAL EDUCATION PROGRAM
}

\begin{abstract}
The Tutorial Education Program - Civil Engineering ("PET"-Civil) emerged as a way of joining experiences by aggregating the spheres of teaching, research and extension in an academic environment, allowing the student to live experiences external to the classroom. Over the years and with the constant evolution of the various forms of integration between student, faculty and society, the program has undergone several changes in the way it reaches the academic community - it is therefore necessary to evaluate the way the program and the participation of students influences personal progress and the quality of graduation as a whole. The following work aims to evaluate the impacts of the participation of PET-Civil groups on the professional, academic and personal development of its graduates throughout the years 2019 and 2020, seeking to understand, mainly, if the group has been fulfilling its objectives as outlined by the Ministry of Education and whether it had a positive influence on the development of its participants, through results obtained through a survey conducted with 15 (fifteen) egress students from different Pet-Civil groups. The research had as main points addressed the profile of the students involved and the group's impact on their academic formation, considering mainly academic average and entry into the market and continuity of studies (postgraduate courses).
\end{abstract}

Keywords: Tutorial Education Program. Civil Engineering. Academic Education. Teaching. Education. 